\title{
The Relationship between 10 Years Risk of Cardiovascular Disease and Schizophrenia Symptoms: Preliminary Results
}

\author{
Esin Evren Kilicaslan ${ }^{\bowtie}$, Merve Karakilic, and Almila Erol \\ Department of Psychiatry, Atatürk Education and Training Hospital, Izmir Katip Celebi University, Izmir, Turkey
}

\begin{abstract}
Objective Previous research shows that patients with schizophrenia have increased cardiovascular disease risk than general population. Increased cardiovascular risk in schizophrenia patients have been associated with many reasons such as antipsychotic drugs, genetic predisposition, andlifestyle. In this study, we aimed to investigate the relationship between the risk of heart disease and schizophrenia symptomatology.

Methods The 10-year cardiovascular risk was assessed by the Framingham Risk Score (FRS) in 103 patients with schizophrenia and in 39 healthy controls. Sociodemographic characteristics, age at schizophrenia onset, duration of illness, number of hospitalizations, the course of the disease and antipsychotic medications were recorded. Patients' symptoms were evaluated via The Scale for the Assessment of Negative Symptoms (SANS), The Scale for the Assessment of Positive Symptoms (SAPS), and Calgary Depression Scale for Schizophrenia (CDSS).

Results Ten-year cardiovascular risk was $5.16 \%$ inpatients with schizophrenia, and $3.02 \%$ in control group ( $\mathrm{p}=0.030$ ). No significant correlation was found between FRS scores, SANS, SAPS, and CDSS scores. However, FRS scores were significantly correlated with age, number of hospitalizations and duration of disease $(r=0.300,0.261,0.252$, respectively). Moreover FRS scores were higher $(\mathrm{p}=0.008)$ and highdensity lipoprotein (HDL) levels were lower $(\mathrm{p}=0.048)$ in patients using multiple antipsychotics.

Conclusion Our findings suggest a relationship between the risk of cardiovascular disease and the duration and overall severity of schizophrenia and also highlights the role of antipsychotics in this relationship.

Psychiatry Investig 2019;16(12):933-939
\end{abstract}

Key Words Schizophrenia, Cardiovascular risk, Framingham risk score, Schizophrenia symptoms, Antipsychotic treatment.

\section{INTRODUCTION}

Mortality rate of schizophrenia patients was found to be high, and cardiovascular diseases (CVD) have been shown to play an important role in this early mortality rate increase. ${ }^{1}$ Therefore, schizophrenia is considered to be a disease that shortens life. ${ }^{2}$ Obesity, ${ }^{3,4}$ smoking, ${ }^{5}$ changes in lipid and glucose levels ${ }^{6,7}$ and glucose intolerance due to medication are common in schizophrenia patients. ${ }^{8}$ Due to non-compliance with the treatment, there are also problems in the treatment of existing disturbances. ${ }^{9-11}$

The Framingham risk score (FRS) is a gender-specific multivariate risk factor algorithm that can be used in the clinical

Received: March 12, 2019 Revised: May 20, 2019

Accepted: September 25, 2019

$\triangle$ Correspondence: Esin Evren Kilicaslan, MD

Department of Psychiatry, Atatürk Education and Training Hospital, Izmir Katip Celebi University, 35150, Karabağlar, Izmir, Turkey

Tel: +905338190191, E-mail: esiniyidogan@gmail.com

(a) This is an Open Access article distributed under the terms of the Creative Commons Attribution Non-Commercial License (https://creativecommons.org/licenses/by$\mathrm{nc} / 4.0$ ) which permits unrestricted non-commercial use, distribution, and reproduction in any medium, provided the original work is properly cited. setting to estimate the 10-year risk of CVD and individual cardiovascular events (coronary, cerebrovascular and peripheral artery disease, and heart failure). ${ }^{12}$ The Framingham heart study helped to reduce cardiovascular mortality in developed countries by early detection of cardiovascular risk factors and measurement of this risk using FRS. ${ }^{13}$ FRS has been confirmed in several different populations ${ }^{14-18}$ and more recently in mental patients. ${ }^{19}$ Studies in various countries have shown that the ten-year risk of CVD is significantly higher in schizophrenia patients than in healthy controls. ${ }^{20-23}$

Some studies investigating the risk of CVD have focused on specific subgroups of schizophrenia patients, such as those over 40 years of age, ${ }^{24}$ obese, ${ }^{25}$ or those using various antipsychotics. ${ }^{26-30}$ The current literature has linked the relationship between CVD and schizophrenia to many reasons such as antipsychotic drugs, age and genetic predisposition, unhealthy nutrition, sedentary lifestyles, and smoking. ${ }^{31,32}$ The only study which compared the degree of cardiovascular risk and the prevalence of metabolic syndrome in deficit and non-deficit schizophrenia patients, reported that patients with deficit schizophrenia were more obese and had a higher coronary heart disease 
risk than patients with non-deficit schizophrenia. ${ }^{33}$ From this point of view, it should also be considered whether there is a relationship between positive and negative symptoms and possible CVD risk in schizophrenia.

In this study, we aimed to investigate the relationship between the risk of heart disease and schizophrenia symptomatology by determining the estimated coronary heart disease risk percentages of schizophrenia patients. We hypothesised that patients with higher negative symptoms would face higher CVD risk.

\section{METHODS}

The study was conducted in Psychosis outpatient unit and Community Mental Health Centerof Izmir Katip Çelebi University Atatürk Training and Research Hospital. A total of 109 patients with schizophrenia were included in the study. All the patients were informed about the study, and written informed consent was obtained. A sociodemographic information form was applied to 39 healty controls who did not have a psychiatric disease and who voluntarily agreed to participate in the study and gave written informed consent as a control group.

Sociodemographic information form, clinical evaluation scales and FRS were applied to all the subjects included in the study. Sociodemographic characteristics, age at onset, duration of illness, number of hospitalizations, the course of the disease and antipsychotic medications were recorded by sociodemographic information form. After the records were completed, The Scale for the Assessment of Negative Symptoms (SANS), ${ }^{34}$ The Scale for the Assessment of Positive Symptoms (SAPS), ${ }^{34}$ and Calgary Depression Scale for Schizophrenia (CDSS) $)^{35}$ were given to all participants.

The 10-year probability of developing general cardiovascular disease in both groups was calculated using a gender-specific multivariate risk factor algorithm found on the Framingham Heart Study website at https:/www.mdcalc.com/framinghamrisk-score-hard-coronary-heart-disease. ${ }^{12}$

Since the study was considered as a follow-up study, the same clinical evaluation scales and the Framingham Risk Score calculation were planned to be repeated one year and ten years later. Preliminary cross-sectional results will be reported here. Approval for the analysis was obtained from the Izmir Katip Celebi University, Non-Interventional Clinical Studies Institutional Review Board with number 2018/317.

\section{The Scale for the Assessment of Positive Symptoms (SAPS)}

It has been developed by Andreasen ${ }^{34}$ to measure the level, distribution and severity of positive symptoms in schizophrenia patients. There are four subscales and 34 items. It has been validated for Turkish language..$^{36}$

\section{The Scale for the Assessment of Negative Symptoms (SANS)}

Schizophrenia patients were developed by Andreasen ${ }^{34}$ to measure the level, distribution and severity of negative symptoms. A total of 5 subscales contain 25 items. It has been validated for Turkish language. ${ }^{37}$

\section{Calgary Depression Scale for Schizophrenia (CDSS)}

The CDS is a rating scale with a structured interview designed to assess depression in people with schizophrenia. ${ }^{35}$ Based on responses to questions asked by the interviewer, the patient is assigned a score ranging from zero to three on each item. These are depressed mood, sense of hopelessness, self-depreciation, guilty ideas of reference, pathological guilt, heightened depression in the morning in the morning, early wakening, suicide and an interviewer assessment of depression based on the entire interview. The Turkish validity and reliability study was conducted by Aydemir et al. ${ }^{38}$

\section{Framingham risk score}

It uses the information obtained from both the patient and current case records. 10-year general CVD risk; is calculated according to the gender-specific Cox regression model developed for the 2008 FRS, including the following variables: age, smoking, systolic blood pressure (SBP), total cholesterol and high-density lipoprotein cholesterol (HDL) levels and history of receiving medical treatment for hypertension.

\section{RESULTS}

The mean age of the patients with schizophrenia was $45.1 \pm$ 10.3 years, and that of the control group was $45.6 \pm 10.0$ years. No statistically significant difference was found between the groups in terms of age, gender, HDL and total cholesterol levels, SBP and having hypertension medication (Table 1). However, in comparison to the control group, the patients' group had lower rate of the married participants $(28.2 \%$ and $84.6 \%$, respectively, $\mathrm{p}<0.01$ ), and higher rate of smoking ( $56.3 \%$ and $23.0 \%$, respectively, $\mathrm{p}<0.01$ ) (Table 1). The mean score of FRS in patients with schizophrenia was $5.16 \pm 6.5$, and that of the control group was $3.02 \pm 4.2(\mathrm{p}=0.030)$. Ten patients were receiving anti-hypertensive medications.

No significant correlation was found between FRS scores and SANS, SAPS, and CDSS scores. However significant correlation was found between FRS scores, and age, number of hospitalization and duration of disease $(\mathrm{r}=0.300,0.261,0.252$, respectively).

When logistic regression analysis was performed to deter- 
mine the factors associated with the FRS score in patientswith schizophrenia, age at onset of schizophrenia, the course of the disease, number of hospitalization, duration of disease, SANS, SAPS and CDSS were entered as independent variables; only number of hospitalization and duration of disease were found as significant predictors of FRS (Table 2).

The medication breakdown were as follows: 88 (85.4\%) on atypical antipsychotics, 7 (6.7\%) on typical antipsychotics and $8(7.7 \%)$ on both. Sixty-four $(62.1 \%)$ of the patients were using antipsychotics and 35 (34.0\%) were using antipsychotic and antidepressant, 3 (2.9\%) were using antipsychotic and mood stabilizer, and $1(1.0 \%)$ were using all the three. No statistical significant differences were found between the groups with regard to SANS; SAPS, CDSS, and FRS scores.

When patients on antipsychotic therapy were compared with regard to number of antipsychotics they were using; the patients who were using one antipsychotic therapy had higher HDL levels, and lower FRS scores, higher SAPS scores and higher number of hospitalizations compared to patients using 2 or more antipsychotic drugs ( $\mathrm{p}=0.048,0.008,0.020,0.002$, respectively). There were no statistically significant differences with regard to the number of antipsycotics used and age, age at schizophrenia onset, duration of disease, tolal cholesterol, SBP, SANS, CDSS (Table 3).

We also investigated whether the way of administration of antipsychotics were administered has an effect on FRS. Of the patients in our study, 65 were using only oral antipsychotics, 12 were using only long acting injectable antipsychotics (LAİA), 26 were using both of them, and FRS scores of the groups were as follows respectively; 46.83; 53.79; 64.10. Kolmogorov-Smirnov test showed that the distrubition wasn't normal across categories. Therefore, Kruskal-Wallis test was performed on FRS. There was a significant difference between the three groups $(\mathrm{p}=0.044)$. When the Mann-Whitney $\mathrm{U}$ test was applied to determine which groups the difference originated from, it was found that the difference between patients using oral antipsy-

Table 1. Demographic and clinical characteristics of the groups

\begin{tabular}{|c|c|c|c|c|}
\hline & Schizophrenia & Healthy control & \multirow{2}{*}{$\mathrm{X}$} & \multirow{2}{*}{$\mathrm{p}$} \\
\hline & $\mathrm{N}(\%)$ & $\mathrm{N}(\%)$ & & \\
\hline \multicolumn{5}{|l|}{ Gender } \\
\hline Female & $51(49.5)$ & $21(53.8)$ & 0.212 & 0.645 \\
\hline Male & $52(50.5)$ & $18(46.2)$ & & \\
\hline \multicolumn{5}{|l|}{ Marital status } \\
\hline Married & $29(28.1)$ & $33(84.6)$ & 37.020 & $<0.000^{\dagger}$ \\
\hline Single & $74(71.9)$ & $6(15.3)$ & & \\
\hline \multicolumn{5}{|l|}{ Smoking } \\
\hline Absent & 45 (43.6) & $30(76.9)$ & 12.538 & $<0.000^{\dagger}$ \\
\hline Present & $58(56.4)$ & $9(23.1)$ & & \\
\hline \multicolumn{5}{|l|}{ Hypertension medication } \\
\hline Absent & $93(90.2)$ & $37(94.8)$ & 1.177 & 0.555 \\
\hline Present & $10(9.8)$ & $2(5.2)$ & & \\
\hline Age & $45.1 \pm 10.3$ & $45.6 \pm 10.0$ & & 0.789 \\
\hline HDL cholesterol (mg/dl) & $44.7 \pm 14.3$ & $48.18 \pm 13.6$ & & 0.192 \\
\hline Total cholesterol (mg/dl) & $200.5 \pm 46.9$ & $190.6 \pm 52.9$ & & 0.314 \\
\hline SBP & $118.6 \pm 14.5$ & $115.1 \pm 21.5$ & & 0.357 \\
\hline FRS & $5.16 \pm 6.5$ & $3.02 \pm 4.2$ & & $0.030^{*}$ \\
\hline
\end{tabular}

${ }^{*} \mathrm{p}<0.05,{ }^{\dagger} \mathrm{p}<0.001$. HDL: high-density lipoprotein cholesterol, SBP: systolic blood pressure, FRS: Framingham Risk Score

Table 2. Logistic regression analyses onto FRS scores in patients with schizophrenia

\begin{tabular}{ccccccc}
\hline \multirow{2}{*}{ Model } & \multirow{2}{*}{} & \multicolumn{3}{c}{ Change statistics } \\
\cline { 3 - 7 } & & R Square change & F change & df1 & df2 & Sig. F change \\
\hline 1 & $0.261^{*}$ & 0.068 & 7.334 & 1 & 100 & 0.008 \\
2 & $0.335^{\dagger}$ & 0.044 & 4.870 & 1 & 99 & 0.030 \\
\hline
\end{tabular}

*predictors: (constant), number of hospitalization, ${ }^{\dagger}$ predictors: (constant), number of hospitalization, duration of disease. FRS: Framingham Risk Score 
Table 3. Comparison of patients using single or multiple antipsychotic drugs with regard to SANS, SAPS, CDSS, FRS and disease-related variables

\begin{tabular}{lccl}
\hline Number of antipsychotics & $\geq 2(\mathrm{~N}=46)$ & $<2(\mathrm{~N}=57)$ & $\mathrm{p}$ \\
\hline Age & $44.67 \pm 9.3$ & $45.44 \pm 11.2$ & 0.712 \\
Age of onset & $27.00 \pm 9.0$ & $28.30 \pm 11.1$ & 0.526 \\
Number of hospitalization & $4.37 \pm 4.6$ & $2.05 \pm 2.7$ & $0.002^{\dagger}$ \\
Duration of disease & $17.09 \pm 9.6$ & $16.32 \pm 10.8$ & 0.707 \\
HDL cholesterol & $41.67 \pm 13.7$ & $47.28 \pm 14.3$ & $0.048^{*}$ \\
Total cholesterol & $202.52 \pm 41.4$ & $198.89 \pm 51.3$ & 0.699 \\
SBP & $120.30 \pm 15.9$ & $117.25 \pm 13.3$ & 0.292 \\
FRS score & $7.09 \pm 7.4$ & $3.69 \pm 5.1$ & $0.008^{\dagger}$ \\
SANS & $26.39 \pm 22.3$ & $26.88 \pm 20.0$ & 0.908 \\
SAPS & $14.67 \pm 17.5$ & $7.33 \pm 14.1$ & $0.020^{*}$ \\
CDSS & $3.13 \pm 4.2$ & $2.89 \pm 4.6$ & 0.790 \\
\hline
\end{tabular}

${ }^{*} \mathrm{p}<0.05,{ }^{\mathrm{p}} \mathrm{p}<0.001$. HDL: high-density lipoprotein cholesterol, SBP: systolic blood pressure, FRS: Framingham Rsik Score, SANS: Scale for the Assessment of Negative Symptoms, SAPS: Scale for the Assessment of Positive Symptoms, CDSS: Calgary Depression Scale for Schizophrenia

chotics and patients using both LAİA and oral antipsychotics was significant $(\mathrm{p}=0.011)$.

\section{DISCUSSION}

The results of our study showed that the prevalence of FRS (5.16\%) in schizophrenia patients was significantly higher than the general reference population (3.02\%). This result is consistent with other studies investigating the 10-year risk of cardiovascular disease with FRS in patients with schizophrenia, ${ }^{20-22,39,40}$ and is close to $5.9 \%$, which is the result of the single study in this topic in our country. ${ }^{23}$

To the best of our knowledge, this is the first study to explore the relationship between positive and negative symptoms and possible CVD risk in schizophrenia. In our study, no significant relationship was found between FRS and schizophrenia symptoms. However, 10-year CVD risk was associated with the duration of the disease and the number of hospitalizations. These results show that the 10-year risk of CVD is related to the severity of the disease and the duration of the disease in general, rather than the cross-sectional severity of the disease.

Both genetic and environmental factors are considered in the etiology of CVD that can shorten the life expectancy of patients with schizophrenia. The first studies in the field of genetics and epigenetics are related to the risk factors of CVD such as metabolic syndrome and diabetes mellitus. ${ }^{41}$ Presence of high blood sugar levels in patients with severe mental illness before antipsychotic period, ${ }^{42}$ and impaired glucose tolerance test in first-episode antipsychotic naïve patients ${ }^{43}$ and their healthy relatives ${ }^{44}$ suggest that genetics have an effect on the etiology of cardiovascular risk factors in these patients. In this point of view some studies investigated whether some common candidate genes are present in both schizophrenia and cardiovascular risk factors. Genetic assosiacions were found between atypical antipsychotic-related weight gain and $I N$ SIG2, ${ }^{45} \mathrm{rs} 498177$ single nucleotide polymorphism (SNP) in the serotonin 5-HT2C receptor gene and metabolic syndrome only in female patients with schizophrenia ${ }^{46}$ and endothelial nitric oxide synthetase (eNOS) T-786C genetic variant and endothelial functioning. ${ }^{47}$

In studies on mRNA in schizophrenia, different alterations among mRNA were reported in rats treated with haloperidol, ${ }^{48}$ in the postmortem brains of schizophrenia patients ${ }^{49}$ and also inperipheral blood mononuclear cells in vivo in schizophrenia patients. ${ }^{50}$ In a study investigating the effect of the treatment with antipsychotics on changes in miRNA expression, neurologically and metabolically relevant miRNA-gene interaction networks were identified in patients treated with olanzapine. ${ }^{51}$

There is much more research into the environmental factors in the etiology of CVD in schizophrenia. Tobacco smoking seems to be an important environmental factor for increasing CVD rates given its expected high prevalence within this type of patients. ${ }^{52,53}$ As in the general population, smoking contributes to the reduced life expectancy in patients with schizophrenia. ${ }^{22}$ Our results have shown also an elevated prevalence of smoking tobacco in patients with schizophrenia than in the Turkish general population. These results are consistent with worldwide literature. ${ }^{53-57}$ With smoking, unhealthy behaviors, high-fat, low-fibre diets and lack of exercise; appears to be the other possible environmental causes of CVD, which is observed to be very high among patients with schizophrenia and other serious mental illnesses. ${ }^{20,58,59}$ Consequently, the duration of exposure to these causes also prolongs as the duration of the disease is prolonged. In our study, the relationship between FRS and disease duration may be associated with increased exposure to these factors.

On the other hand, in our study, the use of more than one antipsychotic was also associated with FRS. Previous studies have consistently reported that antipsychotic medication is associated with increased risk for a range of cardiometabolic disorders, ${ }^{60,61}$ and use of antipsychotic polypharmacy and higher antipsychotic dosages are linked to increased cardiovascular-related mortality, ${ }^{62}$ and negative effects on life expectancy ${ }^{63,64}$ in people with schizophrenia and schizophrenia spectrum disorders. Beside this antipsychotic polypharmacy is widely prevalent, is prescribed for long durations, and is an increasing phenomenon among schizophrenia patients, indicating a significant discrepancy with treatment guidelines. ${ }^{65} \mathrm{~A}$ meta-analysis based on 10 observational studies, suggested that antipsychotic use 
might be a potential risk factor of myocardial infarction. ${ }^{66}$

In addition, according to the results of our study, we found that the route of administration of antipsychotics also had an effect on FRS, and patients using both oral and LAİA were found to have a higher risk of heart disease than those using oral therapy alone. However, this difference may be due to polypharmacy rather than the administration of the drug. Previous studies have shown a high prevalence of metabolic syndrome and cardiovascular risk in psychotic patients treated with long-acting injectable antipsychotics. ${ }^{67,68}$ Compared to oral antipsychotic treatment, LAİA has been shown to have more efficacy, less extrapyramidal symptoms and greater weight gain; $; 9,70$ our study was the first comparative study in terms of cardiovascular effects.

Some limitations of the current study should be mentioned. First, this was a cross-sectional analysis. Another limitation concerns possible influences on the relationships between antipsychotics and cardiometabolic health (such as levels of medication adherence, antipsychotic daily defined dose equivalent, duration of exposure to antipsychotic regimens, family risk factors and lifestyle behaviours) are potential unmeasured confounding variables. In addition, the relatively small sample size may have increased the risk of errors and may have prevented the statistical investigation of the effect of each antipsychotic on CVD.

Our results are consistent with the concept that CVD risk is higher in patients with schizophrenia than the general population. ${ }^{1,19,21-24}$ Additionally, our findings show the relationship between CVD and the duration and overall severity of the disease but not the cross- sectional psychopathology, and also highlights the undeniable role of antipsychotics in this relationship. Monitoring of patients on antipsychotic therapy should not only focus on the psychotic symptoms, but should also consider possible cardiac and metabolic disorders associated with the treatment. Physicians should identify specific measures to counteract these negative events, focusing on changes in lifestyle, diet, exercise, and the use of specific drugs to treat metabolic disorders. These measures, if appropriate, may include assessing the change of antipsychotic treatment by the psychiatrist and avoiding polypharmacy as much as possible. Improving our understanding of cardiovascular risk in patients with schizophrenia may help to develop preventive and therapeutic programs in this vulnerable population.

\section{Conflicts of Interest}

The authors have no potential conflicts of interest to disclose.

\section{Author Contributions}

Conceptualization: Esin Evren Kilicaslan. Data curation: Esin Evren Kilicaslan, Merve Karakilic. Formal analysis: Almila Erol. Investigation: Esin Evren Kilicaslan, Almila Erol. Methodology: Esin Evren Kilicaslan, Almila Erol. Project administration: Esin Evren Kilicaslan. Writing-original draft: Esin Evren Kilicaslan, Merve Karakilic. Writing_review \& edit- ing: Esin Evren Kilicaslan, Almila Erol.

\section{ORCID iD}

Esin Evren Kilicaslan https://orcid.org/0000-0003-0110-6280

\section{REFERENCES}

1. Lawrence D, Kisely S, Pais J. The epidemiology of excess mortality in peoplewith mental illness. Can J Psychiatry 2010;55:752-760.

2. Allebeck P. Schizophrenia: a life-shortening disease. Schizophr Bull 1989;15:81-89.

3. Allison DB, Fontaine KR, Heo M, Mentore JL, Cappelleri JC, Chandler LP, et al. The distribution of bodymass index among individuals with and without schizophrenia. J Clin Psychiatry 1999;60:215-220.

4. Coodin S. Body mass index in persons with schizophrenia. Can J Psychiatry 2001;46:549-555.

5. Goldman LS. Medical illness in patients with schizophrenia. J Clin Psychiatry 1999;60:10-15.

6. Sasaki J, Kumagae G, Sata T, Kuramitsu M, Arakawa K. Decreased concentration of high density lipoprotein cholesterol in schizophrenic patients treated with phenothiazines. Atherosclerosis 1984;51:163-169.

7. Lindenmayer JP, Czobor P, Volavka J, Citrome L, Sheitman B, McEvoy JP, et al. Changes in glucose and cholesterol levels in patients with schizophrenia treated with typical or atypical antipsychotics. Am J Psychiatry 2003;160:290-296.

8. Ryan MC, Collins P, Thakore JH. Impaired fasting glucose tolerance in first-episode, drug-naive patients with schizophrenia. Am J Psychiatry 2003; 160:284-289.

9. Jeste DV, Gladsjo JA, Lindamer LA, Lacro JP. Medical comorbidity in schizophrenia. Schizophr Bull 1996;22:413-430.

10. Vieweg V, Levenson J, Pandurangi A, Silverman J. Medical disorders in the schizophrenic patient. Int J Psychiatry Med 1995;25:137-172.

11. Folsom DP, McCahill M, Bartels SJ, Lindamer LA, Ganiats TG, Jeste DV. Medical comorbidity and receipt of medical care by older homeless people with schizophrenia or depression. Psychiatr Serv 2002;53: 1456-1460.

12. Wilson PW, D’Agostino RB, Levy D, Belanger AM, Silbershatz A, Kannel WB. Prediction of coronary heart disease using risk factor categories. Circulation 1998;97:1837-1847.

13. Bitton A, Gaziano T. The Framingham Heart Study's impact on global risk assessment. Prog Cardiovasc Dis 2010;53:68-78.

14. Suka M, Sugimori H, Yoshida K. Application of the updated Framingham risk score to Japanese men. Hypertens Res 2001;24:685-689.

15. Marrugat J, Solanas P, D’Agostino R, Sullivan L, Ordovas J, Cordón F, et al. Coronaryrisk estimation in Spain using a calibrated Framingham function. Rev Esp Cardiol 2003;56:253-261.

16. Liu J, Hong Y, D’Agostino RB, Wu Z, Wang W, Sun J, et al. Predictive value for the Chinese population of the Framingham CHD risk assessment tool compared with the Chinese Multi-Provincial Cohort Study. JAMA 2004;291:2591-2599.

17. Eichler K, Puhan MA, Steurer J, Bachmann LM. Prediction of first coronary events with the Framingham score: a systematic review. Am Heart J 2007;153:722-731.

18. Lee J, Heng D, Ma S, Chew SK, Hughes K, Tai ES. The metabolic syndrome and mortality: the Singapore Cardiovascular Cohort Study. Clin Endocrinol (Oxf) 2008;69:225-230.

19. Goff DC, Sullivan LM, McEvoy JP, Meyer JM, Nasrallah HA, Daumit GL, et al. A comparison of ten-year cardiac risk estimates in schizophrenia patients from the CATIE study and matched controls. Schizophr Res 2005;80:45-53.

20. Osborn DPJ, Hardoon S, Omar RZ, Holt RIG, King M, Larsen J, et al. Cardiovascular risk prediction models for people with severemental illness: results from the prediction and management of cardiovascular risk in people with severe mental illnesses (PRIMROSE) research program. JAMA Psychiatry 2015;72:143-151. 
21. Cohn T, Prud'homme D, Streiner D, Kameh H, Remington G. Characterizing coronaryheart disease risk in chronic schizophrenia: high prevalence of the metabolic syndrome. Can J Psychiatry 2004;49:753-760.

22. Bobes J, Arango C, Garcia-Garcia M, Rejas J. Healthy lifestyle habits and 10-year cardiovascular risk in schizophrenia spectrum disorders: an analysis of theimpact of smoking tobacco in the CLAMORS schizophrenia cohort. Schizophr Res 2010;119:101-109.

23. Yazici MK, Anil Yagcioglu AE, Ertugrul A, Eni N, Karahan S, Karaagaoglu $\mathrm{E}$, et al. The prevalence and clinical correlates of metabolic syndromein patients with schizophrenia: findings from a cohort in Turkey. Eur Arch Psychiatry Clin Neurosci 2011;261:69-78.

24. Jin H, Folsom D, Sasaki A, Mudaliar S, Henry R, Torres M, et al. Increased Framingham 10-year risk of coronary heart diseasein middleaged and older patients with psychotic symptoms. Schizophr Res 2011; 125:295-299.

25. Ratliff JC, Palmese LB, Reutenauer EL, Srihari VH, Tek C. Obese schizophrenia spectrum patients have significantly higher 10-year general cardiovascular riskand vascular ages than obese individuals without severe mental illness. Psychosomatics 2013;54:67-73.

26. Arango C, Bobes J, Aranda P, Carmena R, Garcia-Garcia M, Rejas J. A comparison of schizophrenia outpatients treated with antipsychotics with and withoutmetabolic syndrome: findings from the CLAMORS study. Schizophr Res 2008;104:1-12.

27. Barak Y, Swartz M, Plopsky I. Assessing cardiovascular risks of olanzapine treatment: a 6-month study versus haloperidol in schizophrenia patients. Int Clin Psychopharmacol 2005;20:315-317.

28. Barnett AH, Millar HL, Loze JY, L'Italien GJ, van Baardewijk M, Knapp M. UK cost-consequence analysis of aripiprazole in schizophrenia: diabetes and coronaryheart disease risk projections (STAR study). Eur Arch Psychiatry Clin Neurosci 2009;259:239-247.

29. Correll CU, Frederickson AM, Kane JM, Manu P. Metabolic syndrome and the risk of coronary heart disease in 367 patients treated with second-generationantipsychotic drugs. J Clin Psychiatry 2006;67:575-583.

30. Del Valle MC, Loebel AD, Murray S, Yang R, Harrison DJ, Cuffel BJ. Change in Framingham risk score in patients with schizophrenia: a post hoc analysis of arandomized, double-blind, 6-week trial of ziprasidone and olanzapine. Prim Care Companion J Clin Psychiatry 2006; 8:329-333.

31. McCreadie RG. Diet, smoking and cardiovascular risk in people with schizophrenia: descriptive study. Br J Psychiatry 2003;183:534-539.

32. Laursen TM, Munk-Olsen T, Vestergaard M. Life expectancy and cardiovascular mortality in persons with schizophrenia. Curr Opin Psychiatry 2012;25:83-88.

33. Arangoa C, Bobes J, Kirkpatrick B, Garcia-Garcia M, Rejas J. Psychopathology, coronary heart disease and metabolic syndrome in schizophrenia spectrum patients with deficit versus non-deficit schizophrenia: Findings from the CLAMORS study. Eur Neuropsychopharmacol 2011;21:867-875.

34. Andreasen NC. Methods for assessing positive and negative symptoms. Mod Probl Pharmacopsychiatry 1990;24:73-88.

35. Addington D, Addington J, Maticka-Tyndale E. Reliability and validity of a depression rating scale for schizophrenics. Schizophr Res 1992; 6:201-208.

36. Erkoç Ş, Arkonaç O, Ataklı C, Özmen E. Reliability and validity of the Turkish version of Scale for the Assessment of Positive Symptoms. Düşünen Adam 1991;4:20-24.

37. Erkoç Ş, Arkonaç O, Ataklı C, Özmen E. Reliability and validity of the Turkish version of Scale for the Assessment of Negative Symptoms. Düşünen Adam 1991;4:16-19.

38. Aydemir Ö, Danacı AE, Pırıldar ŞA, Deveci A, İçelli İ. Reliability and validity of the Turkish version of Scale for the Assessment of Calgary Depression Scale for Schizophrenia. Arch Neuropsychiatry 2000;37: 210-213.

39. Tay YH, Nurjono M, Lee J. Increased Framingham 10-year CVD risk in Chinese patients with schizophrenia. Schizophr Res 2013;147:187-
192.

40. Zhao S, Xia H, Mu J, Wang L, Zhu L, Wang A, et al. 10-year CVD risk in Han Chinese mainland patients with schizophrenia. Psychiatry Res 2018;264:322-326.

41. Emul M, Kalelioglu T. Etiology of cardiovascular disease in patients with schizophrenia: current perspectives. Neuropsychiatr Dis Treat 2015;11:2493-2503.

42. Raphael TP, Parsons JP. Blood sugar studies in dementia praecox and manic-depressive insanity. Arch Neurol Psychiatry 1921;5:687-709.

43. Ryan MC, Collins P, Thakore JH. Impaired fasting glucose tolerance in first-episode, drug-naïve patients with schizophrenia. Am J Psychiatry 2003; 160:284-289.

44. Hansen T, Ingason A, Djurovic S, Melle I, Fenger M, Gustafsson O, et al. At-risk variant in TCF7L2 for type II diabetes increases risk of schizophrenia. Biol Psychiatry 2011;70:59-63.

45. Le Hellard S, Theisen FM, Haberhausen M, Raeder MB, Ferno J, Gebhardt S, et al. Association between the insulin-induced gene 2 (INSIG2) and weight gain in a German sample of antipsychotic-treated schizophrenic patients: perturbation of SREBP-controlled lipogenesis in drug-related metabolic adverse effects? Mol Psychiatry 2009;14:308-317.

46. Bai YM, Chen TT, Liou YJ, Hong CJ, Tsai SJ. Association between HTR2C polymorphisms and metabolic syndrome in patients with schizophrenia treated with atypical antipsychotics. Schizophr Res 2011;125:179-186.

47. Burghardt K, Grove T, Ellingrod V. Endothelial nitric oxide synthetase genetic variants, metabolic syndrome and endothelial function in schizophrenia. J Psychopharmacol 2014;28:349-356.

48. Perkins DO, Jeffries CD, Jarskog LF, Thomson JM, Woods K, Newman MA, et al. microRNA expression in the prefrontal cortex of individuals with schizophrenia and schizoaffective disorder. Genome Biol 2007; 8:R27.

49. de Bartolomeis A, Iasevoli F, Tomasetti C, Buonaguro EF. MicroRNAs in schizophrenia: implications for synaptic plasticity and dopamineglutamate interaction at the postsynaptic density. New avenues for antipsychotic treatment under a theranostic perspective. Mol Neurobiol 2015;52:1771-1790.

50. Gardiner E, Beveridge NJ, Wu JQ, Carr V, Scott RJ, Tooney PA, et al. Imprinted DLK1-DIO3 region of 14q32 defines a schizophrenia-associated miRNA signature in peripheral blood mononuclear cells. Mol Psychiatry 2012;17:827-840.

51. Santarelli DM, Liu B, Duncan CE, Beveridge NJ, Tooney PA, Schofield $\mathrm{PR}$, et al. Gene-microRNA interactions associated with antipsychotic mechanisms and the metabolic side effects of olanzapine. Psychopharmacology (Berl) 2013;227:67-78.

52. De Leon J, Diaz FJ. A meta-analysis of worldwide studies demonstrates an association between schizophrenia and tobacco smoking behaviours. Schizophr Res 2005;76:135-157.

53. Chapman S, Ragg M, McGeechan K. Citation bias in reportedsmoking prevalence in people with schizophrenia. Aus N Z J Psychiatry 2009; 43:277-282.

54. de Leon J. Smoking and vulnerability for schizophrenia. Schizophr Bull 2006;22:405-409.

55. Poirier MF, Canceil O, Baylé F, Millet B, Bourdel MC, Moatti C, et al. Prevalence of smoking in psychiatric patients. Prog Neuropsychopharmacol Biol Psychiatry 2002;26:529-537.

56. de Leon J, Susce MT, Diaz FJ, Rendon DM, Velásquez DM. Variables associated with alcohol, drug, and daily smoking cessation inpatients with severe mental illnesses. J Clin Psychiatry 2005;66:1447-1455.

57. Barr AM, Procyshyn RM, Hui P, Johnson JL, Honer WG. Selfreported motivation to smoke in schizophrenia is related to antipsychoticdrug treatment. Schizophr Res 2008;100:252-260.

58. Barnett AH, Mackin P, Chaudhry I, Farooqi A, Gadsby R, Heald A, et al. Missing metabolic and cardiovascular risk in schizophrenia: diabetes, obesity and dyslipidaemia. J Psychopharmacol 2007;21:357-373.

59. Von Hausswolff-JuhlinY, Bjartveit M, Lindström E, Jones P. Schizo- 
phreniaand physical health problems. Acta Psychiatr Scand Suppl 2009;438:15-21.

60. Correll CU, Detraux J, De Lepeleire J, De Hert M. Effects of antipsychotics, antidepressants and mood stabilizers on risk for physical diseases in people with schizophrenia, depression and bipolar disorder. World Psychiatry 2015;14:119-136.

61. Daumit GL, Dickerson FB, Wang NY, Dalcin A, Jerome GJ, Anderson $\mathrm{CA}$, et al. A behavioral weight-loss intervention in persons with serious mental illness. N Engl J Med 2013;368:1594-1602.

62. Ganguly R, Kotzan JA, Miller LS, Kennedy K, Martin B. Prevalence, trends, and factors associated with antipsychotic polypharmacy among Medicaid-eligible schizophrenia patients, 1998-2000. J Clin Psychiatry 2004;65:1-12.

63. Weinmann S, Read J, Aderhold V. Influence of antipsychotics on mortality in schizophrenia: systematic review. Schizophr Res 2009;113:1-11.

64. Baxter A, Harris M, Khatib Y, Brugha T, Bien H, Bhui K. Reducing excess mortality due to chronic disease in people with severe mental illness: meta-review of health interventions. Br J Psychiatry 2016;208: 322-329.

65. Bressington D, Mui J, Tse ML, Gray R, Cheung EF, Chien WT. Cardio- metabolic health, prescribed antipsychotics and health-related quality of life in people with schizophrenia-spectrum disorders: a cross-sectional study. BMC Psychiatry 2016;16:411.

66. Huang KL, Fang CJ, Hsu CC, Wu SI, Juang JJ, Stewart R. Myocardial infarction risk and antipsychotics use revisited: a meta-analysis of 10 observational studies. J Psychopharmacol 2017;31:1544-1555.

67. Wildi H, Najim H. Clinical outcomes of depot and well being clinic. Results of physical health care checks. Psychiatr Danub 201;25(Suppl 2):S174-S177.

68. Sanchez-Martinez V, Romero-Rubio D, Abad-Perez MJ, DescalzoCabades MA, Alonso-Gutierrez S, Salazar-Fraile J, et al. Metabolic syndrome and cardiovascular risk in people treated with long-acting injectable antipsychotics. Endocr Metab Immune Disord Drug Targets 2018;18:379-387.

69. Emsley R, Oosthuizen P, Koen L, Niehaus DJ, Medori R, Rabinowitz J. Oral versus injectable antipsychotic treatment in early psychosis: post hoc comparison of two studies. Clin Ther 2008;30:2378-2386.

70. Rosa F, Schreiner A, Thomas P, Sherif T. Switching patients with stable schizophrenia or schizoaffective disorder from olanzapine to risperidone long-acting injectable. Clin Drug Investig 2012;32:267-279. 